(C) 2020. This manuscript version is made available under the CC-BY-NC-ND 4.0

license http://creativecommons.org/licenses/by-nc-nd/4.0/

\title{
TITLE: Women's experiences with breastfeeding in public: an integrative review
}

\section{Yvonne Hauck}

\section{Zoe Bradfield}

\section{Lesley Kuliukas}

\section{ABSTRACT}

Background: Much evidence around public breastfeeding does not reflect experiences of the key stakeholder, the breastfeeding woman, and focuses upon the audience. Selective evidence has explored breastfeeding experiences revealing challenges with public breastfeeding as a serendipitous finding. Although women's experiences have been explored in specific contexts, insight into commonalities reflective of an international perspective is unknown.

Objective: to explore, review and synthesise published literature on women's experience with public breastfeeding.

Methods: An integrative review allows inclusion of findings beyond empirical evidence. Whittemore and Knafl's approach was used to capture and analyse evidence from varied sources to provide understanding of a phenomenon from diverse methodologies. PubMed, Medline, Ovid emBase, Scopus, Science Direct, the Cumulative Index of Nursing and Allied Health Literature and PsychINFO were searched. Inclusion criteria included publications in English after 2005 offering descriptions of women's experiences. Data evaluation included assessment of literature quality. A constant comparison approach involved comparing, analysing and drawing similar concepts into themes.

Findings: Integration of women's experience with public breastfeeding from 27 publications covering 12 countries revealed two key themes, what women shared as 'enhancing' and 'challenging'. Challenges included four subthemes: 'drawing attention', 'sexualisation of breasts', 'awareness of others' discomfort', and 'efforts not to be seen'. Enhancing incorporated subthemes: 'supportive audience' and 'confidence'. 
Conclusion: Challenges confirm an international commonality that women encounter during public breastfeeding suggesting a multilayered approach addressing community and societal behaviours is required. Insight to enhance public breastfeeding experiences offers direction to improve support.

\section{KEYWORDS}

Breastfeeding, breastfeeding experience, breastfeeding in public, integrative review, women's views

\section{Problem or Issue}

Evidence around breastfeeding in public does not always reflect the key stakeholder, the breastfeeding woman. The attitudes and opinions of the audience are well represented. Women's experiences with breastfeeding in public have been explored in selected contexts; however, insight into commonalities reflective of an international perspective is unknown.

\section{What is already known}

Evidence exploring breastfeeding experiences in general has revealed challenges with public breastfeeding as a serendipitous finding. Limited international research has captured women's experiences with public breastfeeding highlighting perceived difficulties.

\section{What this paper adds}

Challenges continue to dominate women's experiences internationally with public breastfeeding. To address challenges will require a multilayered approach focused upon improving community and societal attitudes and support. Insight into women's perceptions of what can enhance their breastfeeding experiences offers direction to target support that can make a difference.

\section{BACKGROUND}

Much of the evidence around the phenomenon of breastfeeding in public does not reflect the experiences of the key stakeholder, the breastfeeding woman. In fact many research studies have focused upon the 'audience' or 'public' rather than the mother as participant. Opinions and attitudes around breastfeeding in public have been explored internationally, predominantly using surveys that have included the perspective of the general public and targeted community groups such as university students, young men, women who had never breastfed, and older adults. 
An overview of international evidence around community attitudes to breastfeeding in public will be outlined. Attitudes and acceptability with breastfeeding in public have been reported from the perspective of Chinese and Canadian communities. An online survey with 2021 adults living in China found that $95 \%$ of respondents felt public places should have lactation rooms, $86 \%$ felt it acceptable for mothers to breastfeed in these rooms; however, $65 \%$ agreed that it was acceptable for women to breastfeed in public. ${ }^{1}$ Canadian adults $(n=1276)$ were surveyed over the telephone regarding their support of breastfeeding in public with $78 \%$ agreeing that is was acceptable in a restaurant and $81 \%$ were supportive of a shopping mall. ${ }^{2}$ However, lower support was apparent in respondents who did not have children, had lower education levels, had a first language other than French or English and were retirees. Another Canadian qualitative study with young university educated men and women $(n=47)$ found breastfeeding in public was viewed with caution as 22 indicated it was acceptable if discreet and 9 clarifying acceptance in a private area such as a designated breastfeeding room or washroom. ${ }^{3}$

Numerous studies have captured the perceptions of the American community on public breastfeeding. An online survey with 502 American men assessed responses to images of breastfeeding and public breastfeeding was viewed less favourably than private breastfeeding. ${ }^{4}$ Adults in Midwestern America encompassing 106 undergraduate students and 80 older adults also regarded public breastfeeding more negatively than private breastfeeding, based upon photographs. ${ }^{5}$ A telephone survey conducted 15 years later demonstrated no change in attitude; 1979 residents of New York found that 50\% were not supportive of public breastfeeding and 33\% were uncomfortable having breastfeeding women near them in a public setting. ${ }^{6}$ Finally another online survey with 1036 American adults, mostly white and well educated, revealed that the women respondents were more comfortable with breastfeeding in public than the men. ${ }^{7}$

Recent British evidence has incorporated attitudes and opinions shared on social media platforms. Online comments $(n=884)$ relating to a project supporting women's rights to breastfeed in public in the United Kingdom found less than $10 \%$ were supportive of breastfeeding in public 
whereas $82 \%$ were negative. ${ }^{8}$ Breastfeeding within the home was regarded as appropriate and women who breastfeed in public were viewed as "unattractive, lazy, bad parents, lacking in selfrespect and exhibitionist" ${ }^{\prime \prime}$ (p. 52). An analysis of 805 comments from news media websites and parenting forums in response to an incident where a breastfeeding woman was asked to cover up at a London luxury hotel, reported that the United Kingdom (UK) public who were not supportive of breastfeeding in public cited embarrassment, not knowing where to look and disgust at this bodily function, as reasons for their discomfort. ${ }^{9} \mathrm{~A}$ prevailing judgement was that women should respect others by being discreet and covering themselves when breastfeeding.

A final series of five cross sectional studies from 1995 to 2009 incorporating 5496 Australian adults examined trends in attitudes towards breastfeeding in public places. ${ }^{10} \mathrm{~A}$ stable trend was noted over the 14 years of the survey period with $70 \%$ suggesting it was acceptable to breastfeed in shopping centres, restaurants, workplaces and on public transportation. However, women were twice as likely as men to clarify that this acceptability "depends on how obvious it is"10 (p. 186). In fact, $97 \%$ clarified that breastfeeding was acceptable if a separate room was provided.

Factors influencing attitudes toward public breastfeeding have also been examined and reported. A cross-sectional survey with 7190 UK respondents explored factors influencing attitudes and found that acceptance of breastfeeding in public varied according to gender, age, religion, and parental and breastfeeding status. ${ }^{11}$ Age and education as an influence was supported in one American study where lack of comfort was highest with adults with a lower education level and those 65 years and older. ${ }^{6}$ The Australian cross sectional series by Meng et al. ${ }^{10}$ found that women, people older than 44 years, those born outside of Australia and those with lower education levels were more likely to suggest that breastfeeding in public was not acceptable. However in another American study, ethnicity, residential setting, age and education were not associated with comfort levels around breastfeeding in public ${ }^{7}$ suggesting inconclusive international evidence around how these factors are associated with attitudes. 
In summary, evidence is available that highlights perceptions and attitudes of the general public and specific targeted groups around the phenomenon of breastfeeding in public. However, women's voice as the key participant in public breastfeeding is essential to contribute to a full picture of this phenomenon. Selective evidence has explored women's breastfeeding experiences in general revealing challenges of breastfeeding in public as a serendipitous finding. Women's experience of breastfeeding in public has been explored in distinct international contexts; however gaining insight into commonalities reflective of an international perspective based on diverse research approaches is unknown. Therefore, the objective of this integrative review was to explore, review and synthesise published literature on women's experience with breastfeeding in public.

\section{METHODOLOGY}

When attempting to critically analyse and synthesise evidence around a phenomenon, a number of methodological options are available. These include systematic, integrative, narrative, umbrella or scoping reviews. ${ }^{12-14}$ An integrative review offers a unique feature of allowing for the inclusion of more than empirical evidence. In keeping with Whittemore and Knafl's ${ }^{15}$ approach, diverse data sources can be included to provide a holistic understanding of the phenomenon under review which allows for a combination of diverse methodologies. To illustrate, although there is widespread data on social media use, Pretorius et al. ${ }^{16}$ employed an integrative review method to gain understanding of parent use of social media to influence infant and child health, which included primary data sources using grounded theory, ethnography, focus groups, a community based qualitative study, a randomised control trial and cross sectional surveys.

An integrative review methodology guided by the five stage review process suggested by Whittemore and Knafl ${ }^{15}$ was chosen to explore the published literature on women's experience with breastfeeding in public. Although all literature was published, they included peer reviewed research manuscripts or text / opinion based, non-peer reviewed publications. The initial stage ${ }^{15}$ involved clear identification of a problem to inform the aim of the review, which is presented in the background of this paper. A well-defined literature search then followed, to ensure all relevant 
literature related to the topic of interest is captured. The data evaluation stage involved rigorous assessment of the quality of the primary literature sources prior to the data analysis. The constant comparison approach for data analysis is useful for data from varied methodologies, which in the instance of women's experience of breastfeeding in public, offered primarily qualitative findings. ${ }^{15}$ This process involved comparing and analysing similarities and differences in findings from each literature source with the intention of grouping similar categories and drawing concepts together into themes. The final stage involved presentation of the themes to reveal the process of data synthesis and integration.

A two phase literature search strategy was employed for this integrative review, that involved searching electronic databases as well as the extraction of relevant primary sources from citation searches and scrutiny of reference lists. The following databases were searched: PubMed, Medline, Ovid emBase, Scopus, Science Direct, the Cumulative Index of Nursing and Allied Health Literature (CINAHL), and PsychINFO. Search term used included: Wom\#n OR mother AND breastfeeding AND public AND experience; Breastfeeding in public AND mother OR wom\#n; breastfeed\# AND public AND wom\#n OR mother; breastfeeding in public AND wom\#n OR mother AND experience\#. Our inclusion criteria included published literature in English after 2004 that offered descriptions of women's experiences of breastfeeding in public. The year delimiter was chosen in consensus as the period reflected contemporary evidence of women's experiences. We excluded literature that was non-English, published before 2005 and discussion papers, commentaries or literature reviews synthesising an argument but not capturing the stories or voice of women around their experiences. Our initial search resulted in 2362 records with 2296 excluded following title and abstract review and removal of duplicates. Through the steps of identification, screening, eligibility and conducting a full text review for content, we removed a further 66 records. The remaining 38 were appraised for quality using relevant Joanna Briggs Institute (JBI) critical appraisal tools ${ }^{17}$ such as the Checklist for Qualitative Research (ten appraisal items), Checklist for Text and Opinion (six appraisal items), and Checklist for Analytical Cross Sectional Studies (eight 
appraisal items). The evaluation confirmed that each publication met the appraisal items in the appropriate critical appraisal tool. Each publication was evaluated independently by two members of the team using the JBI critical appraisal tools and results were compared. Discrepancies with assessments were brought to a third member who engaged in a review and all three assessments were discussed at team meetings. All inclusions and exclusions were discussed for consensus agreement.

The PRISMA (Preferred Reporting Items for Systematic Reviews and Meta-Analyses) summary of our selection and search results ${ }^{18}$ is presented in Figure 1 confirming that 27 publications were included in this integrative review.

\section{FINDINGS}

Of the 27 publications reviewed, only nine had an aim that specifically explored the issue of breastfeeding in public. The remaining publications focused upon women's experiences or journey with breastfeeding in general and breastfeeding in public emerged as one of the key issues, themes or categories. The 27 publications in this integrated review incorporated qualitative $(n=23)$, quantitative $(n=1)$ and mixed methods $(n=2)$ research manuscripts and one text / opinion based nonpeer reviewed publication in which 26 women shared stories of breastfeeding in public on the Midwifery Today Facebook page. ${ }^{19}$ Two publications reported findings from one phenomenological study in Australia capturing diverse themes that reflected new mothers exclusive breastfeeding journey to six months post birth. ${ }^{20,21}$ The qualitative research designs employed in the selected peer reviewed manuscripts included phenomenology, qualitative descriptive, qualitative exploratory, qualitative narrative, and sequential consensual qualitative. Data collection in these qualitative works included telephone, focus group and one-on-one interviews and written reflections or audio diaries. The two mixed methods studies included data from a survey, focus group or one-on-one interviews and postings on a website. The one quantitative cross-sectional study used a survey in hospital and one month post birth to explore safety and privacy while breastfeeding in public. ${ }^{22}$ The publications included in this integrative review reflected women's experiences from Australia $(n=7)$, the United 
States $(n=6)$, the United Kingdom $(n=4)$, and one publication each from Singapore, Sweden, Ghana, Ireland, Thailand, New Zealand, China, Romania and Canada.

An integration of women's experience with breastfeeding in public developed from review and systematic analysis revealed two key themes, what women shared as enhancing and challenging their willingness to breastfeed in public (Figure 2). A central theme with four subthemes included the 'challenges' whereas two subthemes were extracted that were regarded as 'enhancing' the experience to breastfeed in public. A summary of the characteristics of the 27 publications and integration of findings under these two key themes and corresponding six subthemes is presented in Table 1. Displaying features of included publications and findings provides clarity and is encouraged as a mechanism to enhance transparency, reproducibility and rigor within integrative reviews. ${ }^{15}$

\section{Enhances women's willingness to breastfeed in public}

The findings from nine manuscripts contributed to the subthemes of a 'supportive audience' and eight revealed how 'confidence' enhanced women's willingness to breastfeed in public. British women shared comments that revealed an openness to breastfeeding and how the pleasure of public reactions outweighed the downside of public breastfeeding. ${ }^{23}$ These women also noted how breastfeeding more in public facilitated their confidence in the practice. ${ }^{23}$ Seven Irish women embedded in a formula feeding culture were interviewed about how experiences with breastfeeding in a support group led by a public health nurse focused upon normalising breastfeeding, with subthemes of socialising, sharing and building confidence. ${ }^{24}$ The opportunity to learn and share within this supportive, relaxed and friendly community atmosphere was valued and assisted these Irish women to build confidence and encourage a more positive outlook towards breastfeeding. ${ }^{24}$ First time breastfeeding mothers $(n=22)$ in the UK shared their experience around relationships with others and the social context of breastfeeding in the initial five weeks post birth. ${ }^{25}$ The acceptance of others was acknowledged as making breastfeeding in public possible after initial feelings of uncertainty. This uncertainty was noted by some British women as a problem due to their own lack of confidence. Twenty Australian mothers who were trainee counsellors for the Australian 
Breastfeeding Association (ABA) reflected on their own breastfeeding experiences and acknowledged that as their confidence grew, they felt more able to breastfeed their baby whereever and whenever. ${ }^{26} \mathrm{~A}$ similar concept reflecting how social norms influenced breastfeeding experiences was described by five Australian mothers, who acknowledged that over time their confidence with public breastfeeding increased while they also actively drew closer to people perceived to be supportive. ${ }^{21}$

Strategies to maintain breastfeeding has recognised the importance of support from a partner, family members, local breastfeeding support groups and health professionals, which is further heightened by the need of a supportive audience during public breastfeeding. For example, in an evaluation of the ABA's 'Breastfeeding Welcome Here' program, 23 mothers completed a qualitative survey through social media. ${ }^{27}$ The majority of mothers indicated that seeing this signage reinforced that a supportive audience would be present, which increased their comfort level and confidence to breastfeed. Stories shared on the Journal's social media page around breastfeeding in public from 26 American women was subsequently published as text in MidwiferyToday and offered examples where women were told "how great it was ... and not to feel ashamed"; how proud family members were; the difference a supportive community or town can make; and the impact of someone smiling and offering positive reinforcement while breastfeeding ${ }^{19}$ (p. 68). Confidence was captured in a story where a woman noted that improvement in her breastfeeding skills grew in parallel with her self-assurance resulting in her becoming more comfortable breastfeeding in public.

The majority of women from Ghana (92\%) who participated in a mixed methods study indicated they practiced breastfeeding in public. Findings confirmed that having the support of a spouse or other family member was associated with women being more likely to breastfeed in public. ${ }^{28}$ Content analysis of a FeedFinder database where UK women provided reviews $(n=1757)$ through a mobile phone application for finding, reviewing and sharing places to breastfeed in public also reinforced the importance of a supportive audience. Women used terms like welcoming and helpful staff, and hospitality where drinks were brought to the table while the woman was feeding. ${ }^{29}$ Chinese women's ( $n=27)$ experiences, emotions and expectations of breastfeeding in public revealed 
a theme of expecting emotional support from society members through kindness and friendly manners that avoided staring or discourteous behaviours. ${ }^{30} \mathrm{~A}$ final study addressing the importance of confidence included the breastfeeding experiences of 17 African American women where some were comfortable to breastfeed in public and others were not. Under a theme of "resisting the naysayers", participants shared how they needed to be confident and ignore the opinions and comments of others ${ }^{31}$ (p. 979).

\section{Challenges to women's willingness to breastfeed in public}

The theme of challenges to breastfeed in public dominated the review findings and incorporated four subthemes: 'drawing attention', 'sexualisation of breasts', awareness of others' discomfort' and 'efforts not to be seen' (Table 1). Twenty five of the 27 manuscripts reflecting findings from 12 countries revealed the challenges women experienced around drawing attention while breastfeeding. Challenges captured women's concerns with attention and involved unsolicited opinions, judgemental remarks and being labelled, ${ }^{20,21}$ fear of being confronted, ${ }^{32}$ being stared $\mathrm{at}^{33}$ or approached by strangers. ${ }^{34}$ Issues with confrontations also extended to what could be shared on social media around public breastfeeding. ${ }^{35}$ African American women felt breastfeeding should be a private act and were concerned with the reaction of strangers. ${ }^{36}$ African refugee women living in Australia suggested that the lack of visibility of public breastfeeding made the act shameful, which contributed to the reactions women were receiving. ${ }^{43}$ Evident in the literature was the assumption that breastfeeding in public was not seen as the social norm ${ }^{31}$ and consequently women didn't want to "stand out" ${ }^{38}$ (p. 296). Not drawing attention had the potential of protecting the women from unwanted comments and being judged, as noted within an Australian study where women needed to "guard against judgement" 39 (p. 24).

The language used to reflect how drawing attention was manifested incorporated terms such as odd looks, ${ }^{23}$ weird or horrible looks $s^{40,41}$ or disapproving gaze ${ }^{31}$ particularly the male gaze. ${ }^{25}$ These potential reactions from others and perceptions of stigma ${ }^{40}$ were regarded as negative and concerning to the woman who did not want to draw this attention. Women expressed feeing self- 
conscious, ${ }^{19,42,43}$ unease, ${ }^{19,33}$ uncomfortable and personally embarrassed, ${ }^{24,28,30,38,42,43}$ uncertain, shy, scared and anxious about the reaction of others ${ }^{24,30}$ which could include remarks around being shameless and uncivilised within a Chinese context ${ }^{30}$ or even reflecting primitivism and exhibitionism within a Romanian context. ${ }^{44}$

The potential of drawing attention due to the breasts ${ }^{25,32,40}$ when privacy was not assured was another concern. Obese breastfeeding women in Sweden revealed the mental strain associated potential exposure ${ }^{45}$ potentially related to body image. The importance of protection of privacy for breastfeeding women was confirmed in a survey with American women. ${ }^{22}$ To address the issue of privacy, British women found using a Feedfinder App, shared information regarding feeding-friendly venues and facilitated efforts to avoid unwanted attention and criticism. ${ }^{29}$

The second subtheme under challenges women experienced, regarding sexualisation of the breasts was apparent in 11 of the 27 publications including the United Kingdom, Australia, the United States Romania and China. Although the image of the breast could be seen as sexual or nurturing, ${ }^{31}$ the reality was that breasts were identified as a sexual part of the body ${ }^{20}$ and exposure of the breast could be regarded as objectifying the woman and considered an inappropriate sexual display. ${ }^{23,25}$ The public display of breasts could be seen as negative due to the perceived sexualisation of the breasts. ${ }^{26}$ Romanian women acknowledged that seeing breasts was a cultural symbol of sexuality ${ }^{44}$ and Chinese women noted that sex was a taboo subject in Chinese culture, which did not align with exposing breasts to breastfeed. ${ }^{30}$ An American woman shared her public breastfeeding experience expressing concerns around "cultural prejudice, fear of nipples and sexual arousal"19 (p. 68). Younger mothers less than 26 years of age were particularly sensitive to the assumption that breasts were regarded as sexual objects. ${ }^{34}$ The view around the sexual nature of breastfeeding was reinforced within the media where women who breastfed toddlers or older children were portrayed as "sexually inappropriate and /or psychologically maladjusted" ${ }^{40}$ (p. 232). Based upon the sexual interpretation of the breast, women were encouraged to protect themselves from unwanted male attention..$^{39}$ 
The third subtheme of 'being aware of others' discomfort' also contributed to the challenges women shared around their public breastfeeding experiences. Nineteen of the 27 manuscripts reflected women from the United Kingdom, Australia, Singapore, Ghana, Ireland, the United States, Romania, Canada and China offering findings supporting this subtheme. Under the subtheme of 'drawing attention' women shared their personal feelings of embarrassment and being uncomfortable, whereas in this subtheme women noted their awareness of others' discomfort. Not wanting to disrupt the comfort of others or being sensitive to the shock, disgust or embarrassment of others was acknowledged. ${ }^{23}$ Sometimes women were aware of this discomfort from comments made by strangers ${ }^{21}$ or from observing the uncomfortable reactions from others. ${ }^{28}$ Irish women were mindful of embarrassment within their families and members in Irish society who may find public breastfeeding offensive and unsettling. ${ }^{24}$ This discomfort could include specific groups as noted by African women living in Australia, who felt that men were offended ${ }^{37}$ or a partner who specifically discouraged the mother to breastfeed in public. ${ }^{36}$

Perceptions that public breastfeeding was not acceptable ${ }^{32}$ could be reinforced by situations where women were told that they were being offensive ${ }^{34}$ and inconsiderate for possible uncomfortable witnesses. ${ }^{35,44}$ There were instances where sensationalised, negative media coverage around breastfeeding in public reinforced the message of concern for the observer ${ }^{40}$ and that women were expected to be aware and understanding of what others will think. ${ }^{35,41}$

Findings from a British study asserted the issue of women "managing their newly lactating body" in ways that could reduce the discomfort of others ${ }^{25}$ (p. 462), which for Australian women involved feeding in an appropriate place to avoid causing discomfort to others. ${ }^{39}$ This issue can be particularly challenging for women breastfeeding a toddler or older child where this practice is not tolerated so well ${ }^{26}$ and they can be made acutely aware of this disappointment from relatives. ${ }^{19}$ Other tenuous situations around public breastfeeding and others' comfort levels include workplaces where acceptance is based upon superior's and colleagues' attitudes and how the woman must adapt to absences to breastfeed or express milk. ${ }^{33}$ 
A theme from a study with African American women labelled "resisting the naysayers" highlighted how women were encouraged to try and ignore others' non-supportive opinion or comments from groups such as health professionals ${ }^{31}$ (p. 979). A final example where Chinese women were aware and encouraged to use strategies to help others feel comfortable around them involved measures to be discrete while feeding ${ }^{30}$ which introduces the prevailing subtheme of using efforts not to be seen.

Finally, 25 of the 27 manuscripts reflecting all 12 countries provided findings that contributed to the challenge women experienced around the efforts they endured to not be seen breastfeeding. As the practice of breastfeeding was asserted as belonging in the space of the home ${ }^{23}$ and not in the public sphere, there was an international social expectation of the women needing to hide away from society by being discrete ${ }^{34,39}$ and ensuring the process was concealed ${ }^{24}$ and breasts could not be seen by using a cover, ${ }^{21,25,28,30,32-35,37,39,40,44,45}$ going into a separate environment like a car, nursing/lactation or parenting room, $25,28,30,31,33,40$ using formula or expressed breastmilk in a bottle 20 , 25,42 or making the effort to minimise breastfeeding around others ${ }^{32}$ by returning home to feed away from the public view. ${ }^{20}$ The limited availability of suitable private places to breastfeed was cited by Australian women as a reason for using a bottle. ${ }^{42}$ The importance of the level of privacy available in venues outside of the home was regarded as facilitating efforts from the breastfeeding woman not to be seen. ${ }^{29}$ Results from an American survey focused upon the concerns around privacy and safety around breastfeeding through the use of a cover, a changing room and locking a door. Study participants regarded home as safer place to breastfeed (99\%) than outside of the home (48\%) at one month post birth. ${ }^{22}$

There are specific issues where the need to not be seen was extenuated. Needing to hide away to maintain modesty was recognised as a cultural norm by Australian women that was also related to the age of the child as tolerance to the practice of breastfeeding in public decreased with a toddler or older child. ${ }^{26}$ The need to minimize exposure was important to many women and obese women in particular ${ }^{45}$ due to the challenge of large breasts making discreet breastfeeding more 
difficult. ${ }^{19,43}$ Although Romanian women were in favour of the need to seclude yourself with your baby, ${ }^{44}$ adolescent mothers in Thailand felt isolated by being required to stay home and not go out. ${ }^{38}$ Canadian mothers who were university students also reported feelings of isolation and a desire to connect with other breastfeeding mothers which could be problematic due to efforts not to be seen. ${ }^{41}$

\section{DISCUSSION}

A critical analysis of the findings around international women's experiences of public breastfeeding from 27 publications revealed two main themes capturing what enhanced or challenged women's willingness to breastfeed in public. The aims of twenty two published studies explored women's overall breastfeeding journey where breastfeeding in public emerged as a common theme or category within their experience. In only nine publications were women directly asked about their experience of breastfeeding in public. The subthemes of having a supportive audience and self-confidence, captured under the theme of what enhanced women's willingness to breastfeed in public, were reflected in nine and eight publications, respectively. The evidence to support the subthemes under the challenges theme, such as drawing attention, sexualisation of breasts, awareness of others' discomfort and efforts not to be seen were overwhelmingly represented in twenty five, nineteen and eleven publications. Further research is warranted to specifically ask women what they feel could assist with their intention to breastfeed in public and provide insight into strategies or initiatives that can be promoted to encourage and support breastfeeding women. Additional evidence could also focus upon confirming whether the perceived challenges to public breastfeeding are negatively influencing women's decision to not initiate breastfeeding or to cease breastfeeding before they had originally intended.

Discomfort with the prospect of breastfeeding in public has been suggested as potentially influencing infant feeding choices, planning a shorter breastfeeding duration or making the decision to cease breastfeeding earlier than anticipated. ${ }^{46,47}$ Risk factors for early weaning for Austrian women include early supplemental feedings, perceived milk insufficiency and low breastfeeding self- 
efficacy. ${ }^{48}$ These findings of perceptions of insufficient milk are supported by Australian women's most commonly cited reason for ceasing breastfeeding by nine weeks ${ }^{49}$ and 26 weeks. ${ }^{50}$ Greater understanding around how women interpret that their supply as inadequate is crucial. Boyer ${ }^{51}$ asserts that women's often negative experiences of breastfeeding in public may contribute to low breastfeeding rates in the United Kingdom. As noted under the subtheme 'efforts not to be seen', women may avoid breastfeeding in public by using a bottle of formula to supplement feeding which can contribute to decreasing a woman's milk supply. Further research is needed to determine if perceptions of an inadequate supply are based on interpretations of infant behaviour such as being unsettled and not sleeping as expected or are practices to avoid the challenges faced with breastfeeding in public such as using a bottle thereby compromising milk supply.

Developing confidence to enhance a woman's willingness to breastfeed in public may also be affected by perceived challenges. For example, the phrase 'give it a go culture' has been proposed by British researchers to describe women who feel they may not develop the confidence needed to continue breastfeeding due to challenges with managing public breastfeeding in addition to physical difficulties with attachment or sore nipples. ${ }^{52}$ Self-efficacy or confidence in their own ability to accomplish a task was positively associated with exclusive breastfeeding, whereas having a short intention and lower self-efficacy were predictors of breastfeeding cessation within the first six months post birth with Taiwanese women. ${ }^{53}$ Similar results were found in an Irish study where women who were older ( $>35$ years) had a positive attitude toward infant feeding and a high selfefficacy score, were more likely to breastfeed for as long as they had intended. ${ }^{54}$ Maternal breastfeeding confidence, combined with newborn breastfeeding behaviour such as readiness to feed or arousability, rooting, latching and an effective sucking pattern are strong predictors of breastfeeding duration. ${ }^{55}$ Conversely, women intending to bottle feed have lower self-efficacy regarding breastfeeding and cited convenience as the reason for their infant feeding choice. ${ }^{56}$ Maternal confidence is not only essential for public breastfeeding but is a key contributor to enhance and promote a positive breastfeeding experience. A systematic review and meta-analysis confirmed 
that higher maternal breastfeeding self-efficacy is not only associated with better breastfeeding outcomes but is a modifiable factor that can be targeted with interventions to improve self-efficacy and breastfeeding rates. ${ }^{57}$

Although interventions within the Baby Friendly Health Initiative have been found to increase exclusive breastfeeding for six months by combining emotional support and counselling for women and ensuring assistance by appropriately trained professionals, ${ }^{58}$ these interventions focus upon the individual woman. Adapting the African proverb of 'it takes a village to raise a child' 59 to 'it takes a village to breastfeed' aligns with the subtheme of having a 'supportive audience' and acknowledges the importance of societal engagement and support. A proposed ecological breastfeeding model encompassing the mother/infant dyad, family, health care system, community and societal/cultural levels asserts that interventions to support breastfeeding must exceed the individual level and simultaneously address all levels. ${ }^{60}$ An international study exploring what Australian, Irish and Swedish women perceive assisted them to breastfeed for six months confirmed that support is complex, multi-faceted and extends from the individual woman's self-determination and knowledge to partner support, reassurance their baby was thriving and enjoying breastfeeding to informal and formal support and finally, the outer layer of societal support where breastfeeding is seen as the cultural norm. ${ }^{61}$

In recognition of the importance of layered support, a multifaceted approach was recommended in a Western Australian Health Promotion Strategic Framework to foster an environment supportive of breastfeeding by including education and support for mothers, promoting supportive community and family environments, and enforcing restrictions on marketing and labelling of infant formula ${ }^{62}$ (p. 29). Further support is apparent in a priority action within the Australian National Breastfeeding Strategy that endorses a national social marketing campaign to target specific audiences and change attitudes and behaviours unsupportive of breastfeeding. ${ }^{63}$ Women's experiences with breastfeeding in public must be acknowledged and acted upon. Existing strategies such as the 'breastfeeding welcome here' sticker are one positive example that 
ensures women know they are welcome to breastfeed, increases awareness of laws that protect the rights of breastfeeding women, and encourages advocates for breastfeeding which is essential for breastfeeding to be considered the cultural norm. ${ }^{64}$ Behaving outside of the "societal norm" (P.39) prevented women in a qualitative English study from breastfeeding in public ${ }^{65}$ and until the negative public perception is changed women will be fearful ${ }^{65}$. Boyer ${ }^{47}$ ( $p 430$ ) asserts that "the way to break the taboo is to do the taboo thing" and $\operatorname{Amir}^{46}$ (p. 187) argues that we need to make breastfeeding more visible and "unremarkable". In fact, results from a survey with Scottish women who had never breastfed confirmed that seeing other women breastfeed within the previous year was associated with a positive attitude where they agreed with a statement "it was lovely to see her breastfeed"66 (p. 134).

\section{STRENGTHS AND LIMITATIONS}

The strengths of this review lie in the rigorous application of the well-recognised and accepted framework for Integrative Review by Whittmore and Knafl. ${ }^{15}$ The function of integrative review frameworks to draw together evidence and a variety of critically appraised sources of knowledge contributes to the 'roundedness' of the review findings. The methodology also offers distinct utility for the rigorous and systematic retrieval, evaluation, analysis and synthesis of data for the nine international studies that specifically explored breastfeeding in public. As noted, the remaining publications in the integrative review explored women's overall breastfeeding journey revealing that breastfeeding in public was a common theme or category during their experience. The authorship team, all experienced researchers achieved consensus on each step of the process from search strategy to formation of themes which is a robust approach to integrative reviewing. The findings of this review have served to synthesise current knowledge around women's experiences of breastfeeding in public as well as signposting recognised gaps in current evidence highlighting areas for future research. A limitation may be considered as the review of publications only in English language resulting in evidence available in other languages not being included.

\section{CONCLUSION}


Integration of women's experience with public breastfeeding across diverse international contexts has revealed two key themes around what enhanced and challenged their willingness to breastfeed in public. Challenges presents as a prevailing theme with four subthemes: 'drawing attention', 'sexualisation of breasts', 'awareness of others' discomfort', and 'efforts not to be seen'. Women's perceptions of what enhanced their experience of public breastfeeding, namely confidence and a supportive audience, offers preliminary insight to inform strategies that could negate the challenges, while fostering women's confidence and building a community where breastfeeding is recognised as a cultural norm. Further research to build our knowledge around what women want and need around support with breastfeeding in public must be considered a priority by governments and agencies promoting breastfeeding. 


\section{REFERENCES (WOMBI editorial approval for extended reference list)}

1. Zhao $Y$, Ouyang $Y-Q$, Redding SR. Attitudes of Chinese adults to breastfeeding in public: a web-based survey. Breastfeeding Medicine. 2017;12(5):316-21. doi:10.1089/bfm.2017.0013.

2. Russell K, Ali A. Public attitudes toward breastfeeding in public places in Ottawa, Canada. Journal of Human Lactation. 2017;33(2):401-8. doi:10.1177/0890334417695203.

3. Spurles PK, Babineau J. A qualitative study of attitudes toward public breastfeeding among young Canadian men and women. Journal of Human Lactation. 2011;27(2):131-7. doi:10.1177/0890334410390044.

4. Magnusson BM, Thackeray CR, Van Wagenen SA, Davis SF, Richards R, Merrill RM. Perceptions of public breastfeeding images and their association with breastfeeding knowledge and attitudes among an internet panel of men ages 21-44 in the United States. Journal of Human Lactation. 2017;33(1):157-64. doi:10.1177/0890334416682002.

5. Acker M. Breast is best... but not everywhere: ambivalent sexism and attitudes toward private and public breastfeeding. Sex Roles. 2009;61(7-8):476-90.

6. Mulready-Ward C, Hackett M. Perception and attitudes: breastfeeding in public in New York city. Journal of Human Lactation. 2014;30(2):195-200. doi:10.1177/0890334414524988.

7. Roche A, Owen K, Fung T. Opinions toward breastfeeding in public and appropriate duration. Infant, Child and Adolescent Nutrition. 2015;7:44-53.

8. Grant A. "I...don't want to see you flashing your bits around": exhibitionism, othering and good motherhood in perceptions of public breastfeeding. Geoforum. 2016;71:52-61.

9. Morris C, Zaraté de La Fuente GA, Williams CET, Hirst C. UK Views toward breastfeeding in public: an analysis of the public's response to the Claridge's incident. Journal of Human Lactation. 2016;32(3):472-80. doi:10.1177/0890334416648934.

10. Meng X, Daly A, Pollard CM, Binns CW. Community attitudes toward breastfeeding in public places among Western Australia adults, 1995-2009. Journal of Human Lactation. 2013;29(2):183-9. doi:10.1177/0890334413478835. 
11. Morris C, Schofield P, Hirst C. Exploration of the factors influencing attitudes to breastfeeding in public. Journal of Human Lactation. 2019. doi:10.1177/0890334419878119.

12. Munn Z, Peters M, Stern C, Tufanaru C, McArthur A, Aromataris E. Systematic review or scoping review? Guidance for authors when choosing between a systematic or scoping review approach. BMC Med Res Methodol. 2018;18(1). doi.org/10.1186/s12874-018-611-x.

13. Snyder H. Literature review as a research methodology: an overview and guidelines. Journal of Business Research. 2019;104:333-9. doi.org/10.1016/j.jbusews.2019.07.039.

14. Whittmore R, Chao A, Jang M, Minges KE, Park C. Methods for knowledge synthesis: An overview. Heart Lung: Journal of Acute Critical Care. 2014;43(5):453-61. doi.org/10.1016/j.hrtlng.2014.05.014.

15. Whittmore R, Knafl K. The integrative review: updated methodology. Journal of Advanced Nursing. 2005;52(5):546-53.

16. Pretorius K, Johnson KE, Rew L. An integrative review: understanding parental use of aocial media to influence infant and child health. Maternal and Child Health Journal. 2019;23(10):1360. doi.org/10.1007/s10995-019-02781-w.

17. Joanna Briggs Institute JB. JBI Critical Appraisal Tools. 2016; https://joannabriggs.org/research/critical-appraisal-tools.html

18. Moher D, Liberati A, Tetzlaff J, Altman DG. Preferred reporting items for systematic reviews and meta-analyses : the PRISMA statement. PLoS Med, 2009; 6 (7), e1000097. doi:10.1371/journal.pmed1000097.

19. Tritten J. How did/do you feel when breastfeeding in public? Midwifery Today. 2014;112:679. http://search.ebscohost.com.dbgw.lis.curtin.edu.au/login.aspx?direct=true \&db=rzh\&AN=10 7841631\&site=ehost-live 
20. Charlick S, Pincombe J, McKellar L, Gordon A. Navigating the social complexities of breastfeeding: an interpretative phenomenological analysis of women's experiences. Evidence Based Midwifery. 2018;16(1):21-8.

http://search.ebscohost.com.dbgw.lis.curtin.edu.au/login.aspx?direct=true\&db=rzh\&AN=12 9106094\&site=ehost-live

21. Charlick SJ, McKellar L, Gordon AL, Pincombe J. The private journey: An interpretative phenomenological analysis of exclusive breastfeeding. Women and Birth. 2019;32(1):e34e42. doi-org.dbgw.lis.curtin.edu.au/10.1016/j.wombi.2018.03.003.

22. Rosen-Carole C, Allen K, Fagnano M, Dozier A, Halterman J. Mothers' concerns for personal safety and privacy while breastfeeding: an unexplored phenomenon. Breastfeeding Medicine. 2018;13(3):181-8. doi:10.1089/bfm.2017.0187.

23. Boyer K. Affect, corporeality and the limits of belonging: Breastfeeding in public in the contemporary UK. Health Place. 2012;18(3):552-60. .doi:10.1016/j.healthplace.2012.01.010

24. Leahy-Warren P, Creedon M, O'mahony A, Mulcahy H. Normalising breastfeeding within a formula feeding culture: An Irish qualitative study. Women and Birth. 2017;30(2):e103-e10. doi:10.1016/j.wombi.2016.10.002.

25. Leeming D, Williamson I, Lyttle S, S. J. Socially sensitive lactation: exploring the social context of breastfeeding. Psychology and Health. 2013;28(4):450-68.

doi:10.1080/08870446.2012.737465.

26. Prendergast $E$, James J. Engaging mothers: Breastfeeding experiences recounted (EMBER). A pilot study. Breastfeeding Review. 2016;24(2):11-9.

27. Stevenson LE. The Australian breastfeeding association's breastfeeding welcome here program in rural South-West Victorian settings. Breastfeeding Review. 2019;27(1):7-11.

28. Coomson JB, Aryeetey R. Perception and practice of breastfeeding in public in an urban community in Accra, Ghana. International Breastfeeding Journal. 2018;13(1):18-27. doi:10.1186/s13006-018-0161-1. 
29. Simpson E, Garbett A, Comber, Balaam M. Factors important for women who breastfeed in public: a content analysis of review data from FeedFinder. BMJ Open. 2016;6. e011762. doi:10.1136/bmjopen-2016-011762

30. Zhao $Y$, Ouyang $Y-Q$, Redding SR. Chinese women's experiences, emotions and expectations of breast-feeding in public: a qualitative study. 2018;21(8):1565-72. doi:10.1017/S1368980017003937.

31. Spencer B, Wambach K, Domain EW. African American women's breastfeeding experiences: cultural, personal, and political voices. Qualitative Health Research. 2015;25(7):974-87. doi:10.1177/1049732314554097.

32. McKenzie SA, Rasmussen KM, Garner CD. Experiences and perspectives about breastfeeding in "Public": a qualitative exploration among normal-eeight and obese mothers. Journal of Human Lactation. 2018;34(4):760-7. doi:10.1177/0890334417751881.

33. Choo P, Ryan K. A qualitative study exploring first time mothers' experiences of breastfeeding in Singapore. Proceedings of Singapore Healthcare. 2016;25(1):5-12.

34. Noble-Carr D, Bell C. Exposed: younger mothers and breastfeeding. Breastfeeding Review. 2012;20(3):27-38.

35. Owens N, Carter S, Nordham C, Ford J. Neutralizing the maternal breast: accounts of public breastfeeding by African American mothers. Journal of Family Issues. 2018;39(2):430-50. doiorg.dbgw.lis.curtin.edu.au/10.1177/0192513X16650229.

36. Lewallen LP, Street DJ. Initiating and sustaining breastfeeding in African American women. Journal of Obstetric, Gynecologic, \& Neonatal Nursing. 2010;39(6):667-74. https://doiorg.dbgw.lis.curtin.edu.au/10.1111/j.1552-6909.2010.01196.x

37. Gallegos D, Vicca N, Streiner S. Breastfeeding beliefs and practices of African women living in Brisbane and Perth, Australia. Maternal \& Child Nutrition. 2015;11(4):727-36. doiorg.dbgw.lis.curtin.edu.au/10.1111/mcn.12034. 
38. Nuampa S, Tilokskulchai F, Sinsuksai N, Patil CL, Phahuwatanakorn W. Breastfeeding experiences among Thai adolescent mothers: A descriptive qualitative study. Pacific Rim International Journal of Nursing Research. 2018;22(4):288-303.

39. Sheehan A, Gribble K, Schmied V. It's okay to breastfeed in public but ..... . International Breastfeeding Journal. 2019;14. doi.org/10.1186/s1300-019-0216-y.

40. Newman KL, Williamson IR. Why aren't you stopping now?!' Exploring accounts of white women breastfeeding beyond six months in the East of England. Appetite. 2018;129:228-35. doi-org.dbgw.lis.curtin.edu.au/10.1016/j.appet.2018.06.018.

41. West JM, Power J, Hayward K, Joy P. An exploratory thematic analysis of the breastfeeding experience of students at a Canadian university. Journal of Human Lactation. 2017;33(1):20513. doi:10.1177/0890334416679621.

42. Forster DA, McLachlan HL. Women's views and experiences of breast feeding: positive, negative or just good for the baby? Midwifery. 2010;26(1):116-25. doi:10.1016/j.midw.2008.04.009.

43. Massov L. Clinically overweight and obese mothers and low rates of breastfeeding: Exploring women's perspectives. New Zealand College of Midwives Journal. 2015;51:23-9. doiorg.dbgw.lis.curtin.edu.au/10.12784/nzcomjn|51.2015.4.23-29.

44. Tăut D. Breastfeeding (Un)covered: narratives of public breastfeeding on Romanian discussion forums. Official Journal of the International Society of Behavioral Medicine. 2017;24(6):815-26. doi:10.1007/s12529-017-9687-7.

45. Claesson I-M, Larsson L, Steen L, Alehagen S. "You just need to leave the room when you breastfeed" Breastfeeding experiences among obese women in Sweden - A qualitative study. BMC Pregnancy and Childbirth. 2018;18(1). doi: 10.1186/s12884-017-1656-2.

46. Amir L. Breastfeeding in public: "You can do it?". International Breastfeeding Journal. 2014;9(1). doi:10.1186/s13006-014-0026-1. 
47. Boyer K. "The way to break the taboo is to do the taboo thing" breastfeeding in public and citizen-activism in the UK. Health and Place. 2011;17(2):430-7. doi:10.1016/j.healthplace.2010.06.013.

48. Karall D, Ndayisaba J-P, Heichlinger A, Kiechl-Kohlendorfer U, Stojakovic S, Leitner H, et al. Breastfeeding duration: early weaning-do we sufficiently consider the risk factors? Journal of Pediatric Gastroenterology and Nutrition. 2015;61(5):577-82.

doi:10.1097/MPG.0000000000000873.

49. Hauck Y, Fenwick J, Dhaliwal S, Butt J. A Western Australian survey of breastfeeding initiation, prevalence and early cessation patterns. Maternal and Child Health Journal. 2011;15(2):260-8. doi:10.1007/s10995-009-0554-2.

50. Newby RM, Davies PSW. Why do women stop breast-feeding? Results from a contemporary prospective study in a cohort of Australian women. European Journal of Clinical Nutrition. 2016;70(12): 1428-1432.

51. Boyer K. The emotional resonances of breastfeeding in public: The role of strangers in breastfeeding practice. Emotion, Space and Society. 2018;26:33-40.

52. Bailey C, Pain RH, Aarvold JE. A 'give it a go' breast-feeding culture and early cessation among low-income mothers. Midwifery. 2004;20(3):240-50.

53. Tsai T-I, Huang S-H, Lee S-YD. Maternal and hospital factors associated with first-time mothers' breastfeeding practice: a prospective study. Breastfeeding Medicine. 2015;10(6):334-40. doi:10.1089/bfm.2015.0005

54. Leahy-Warren P, Mulcahy H, Phelan A, Corcoran P. Factors influencing initiation and duration of breast feeding in Ireland. Midwifery. 2014;30(3):345-52. doi:10.1016/j.midw.2013.01.008.

55. Loke AY, Chan LKS. Maternal breastfeeding self-efficacy and the breastfeeding behaviors of newborns in the practice of exclusive breastfeeding. Journal of Obstetric, Gynecologic, \& Neonatal Nursing. 2013;42(6):672-84. doi:10.1111/1552-6909.12250. 
56. Cabieses B, Waiblinger D, Santorelli G, McEachan R. What factors explain pregnant women's feeding intentions in Bradford, England: a multi-methods, multi-ethnic study. BMC Pregnancy and Childbirth. 2014;14: 50. http://www.biomedcentral.com/1471-2393/14/50

57. Brockway M, Benzies K, Hayden KA. Interventions to improve breastfeeding self-efficacy and resultant breastfeeding rates: a systematic review and meta-analysis. Journal of Human Lactation. 2017;33(3):486-99. doi:10.1177/0890334417707957.

58. Kim S, Park S, Oh J, Kim J, Ahn S. Interventions promoting exclusive breastfeeding up to six months after birth: a systematic review and meta-analysis of randomised controlled trials. International Journal of Nursing Studies. 2018;80:94-105. doi:10.1016/j.ijnurstu.2018.01.004.

59. African proverbs, sayings and stories. 1998. Accessed on November 22, 2019 from https://www.afriprov.org/african-proverb-of-the-month/23-1998proverbs/137-november1998-proverb.html

60. Tiedje L, Schiffman R, Omar M, Wright J, Buzzitta C, McCann A, et al. An ecological approach to breastfeeding. American Journal of Maternal Child Nursing. 2002;27(3):154-61.

61. Hauck Y, Blixt I, Hildingsson I, Gallagher L, Rubertsson C, Thomson B, et al. Australian, Irish and Swedish women's perceptions of what assisted them to breastfeed for six months: exploratory design using critical incident technique. BMC Public Health 2016;16. doi:10.1186/s12889-016-3740-3.

62. Chronic Disease Prevention Directorate. Western Australian Health Promotion Strategic Framework 2017-2021. Perth: Department of Health, Western Australia; 2017. https://ww2.health.wa.gov.au/ /media/Files/Corporate/Reports\%20and\%20publications/HP SF/WA-Health-Promotion-Strategic-Framework-2017-2021.pdf

63. Council of Australian Governments [COAG] Health Council. 2019. Australian National Breastfeeding Strategy: 2019 and Beyond. Canberra, Department of Health. https://apo.org.au/sites/default/files/resource-files/2019/08/apo-nid253556-1379891.pdf 
64. Brodribb WE. Why is breastfeeding in public such a big deal? Breastfeeding Medicine. 2015;10(4):229. doi:10.1089/bfm.2015.9991.

65. Thomson G, Katherine Ebisch-Burton K, Flacking R. Shame if you do - shame if you don't: women's experiences of infant feeding. Maternal and Child Nutrition (2015), 11, pp. 33-46 doi:10.1111/mcn.12148

66. Hoddinott P, Kroll T, Raja A, Lee AJ. Seeing other women breastfeed: how vicarious experience relates to breastfeeding intention and behaviour. Maternal \& Child Nutrition. 2010;6(2):134-46. 